\title{
The effects of functional training and stationary cycling on respiratory function of elderly with Parkinson disease: a pilot study
}

\author{
Os efeitos do treino funcional e da bicicleta \\ estacionária na função respiratória de idosos com \\ Doença de Parkinson: um estudo piloto
}

Raíssa Almeida da Silveira, Karen Valadares Trippo, Gabriel Pereira Duarte, Mansueto Gomes Neto, Jamary Oliveira Filho, Daniel Dominguez Ferraz ${ }^{*}$

Universidade Federal da Bahia (UFBA), Salvador, BA, Brazil

\begin{abstract}
Introduction: Respiratory function changes in patients with Parkinson's disease (PD) contribute to aspiration pneumonia, the main cause of mortality in PD population. Objective: To compare the effects of functional training and cycle exercise in respiratory function of elderly with PD. Methods: Twenty participants were randomised into two groups. Experimental group (EG) (n = 10) performed cycle exercise and control group (CG) $(n=10)$ was trained with functional training. A blinded researcher evaluated maximal inspiratory pressure (MIP), maximal expiratory pressure (MEP), thoracoabdominal amplitude, forced vital capacity (FVC) and forced expiratory volume in the first second (FEV 1 ) before and after interventions. Results: Both groups did not improve significantly respiratory function. Only CG improved significantly FVC ( $p=0.01)$. No differences were found between groups. Conclusion: 8-week exercise programs are not able to improve the respiratory function of elderly in 2 to 3 PD
\end{abstract}

\footnotetext{
RAS: BS, e-mail: raissafisio11@gmail.com

KVT: Doctoral student, e-mail: karentrippo@superig.com.br

GPD: BS, e-mail: gabriel.duarte@ufba.br

MGN: PhD, e-mail: netofisio@gmail.com

JOF: PhD, e-mail: jamary@mail.harvard.edu

DDF: Doctoral student, e-mail: danieldf@ufba.br
} 
Hoehn \& Yahr stage. Both functional training and cycle exercise do not to improve respiratory function in elderly with PD.

Keywords: Aged. Exercise. Respiratory Function Tests.

\title{
Resumo
}

\begin{abstract}
Introdução: Mudanças na função respiratória em pacientes com Doença de Parkinson (DP) contribuem para a pneumonia aspirativa, principal causa de mortalidade nessa população. Objetivo: Comparar os efeitos do treino funcional e do exercício em bicicleta estacionária na função respiratória de idosos com Doença de Parkinson (DP). Métodos: 20 participantes foram randomizados em 2 grupos. 0 grupo experimental $(G E)(n=10)$ realizou exercício em bicicleta estacionária e o grupo controle $(G C)(n=10)$ realizou o treino funcional. Um pesquisador cegado avaliou a pressão inspiratória máxima (PIM), a pressão expiratória máxima (PEM), a amplitude toracoabdominal, a capacidade vital forçada (CVF) e o volume expiratório forçado no primeiro segundo ( $\left.V E F_{1}\right)$ antes e após as intervenções. Resultados: Ambos os grupos não melhoraram significativamente a função respiratória. Apenas o GC melhorou de forma significante a CVF ( $p=0.01)$. Nenhuma diferença foi encontrada entre os grupos. Conclusão: Programas de exercício com duração de 8 semanas não são capazes de melhorar a função respiratória de idosos com DP nos estágios 2 a 3 de Hoehn \& Yahr. Ambos grupos que realizaram o treino funcional e exercício em bicicleta estacionária não melhora a função respiratória de idosos com DP.
\end{abstract}

Palavras-chave: Idoso. Exercício. Testes de Função Respiratória.

\section{Introduction}

Parkinson's disease (PD) patients present neurological symptoms as resting tremor, rigidity, bradykinesia and postural instability which intensify with disease progression [1]. These patients also have respiratory dysfunction, a major cause of mortality in this population. They tend to reduce their daily activities and do not notice these breathing dysfunctions in early disease stages [2].

Chest expansion decrease, and lung volumes reduction may induce respiratory changes in patients with PD. Trunk and spine mobility restriction, osteoarticular degeneration and trunk flexion posture can also compromise the inspiration and expiration movements inducing respiratory dysfunctions [3]. Patients with PD presented reduction in cough effectiveness and decreasing in peak electromyography amplitude of abdominal muscles during voluntary and induced cough4. These changes hinder the removal of airway secretions by the respiratory system, contributing to aspiration pneumonia, the main cause of mortality in PD population [4].
Although PD is an irreversible and neurodegenerative disease, pharmacological and non-pharmacological treatment can help to minimize and control its signs and symptoms. Neurorehabilitation is a complement to drug treatment and works primarily to prevent or reduce disease complications [5]. The conventional therapeutic exercises aim to maintain the physical conditioning, preserve the activity and musculoskeletal flexibility and improve postural balance [6].

A recent systematic review showed the effects of different physical therapy modalities on mobility, activities of daily living, gait, quality of life, balance, risk of falls and disease severity of PD subjects [7]. The exercise is generally accepted as an intervention that could help both motor and non-motor complications of PD and may be regarded as a basic element of any rehabilitative approach [8]. A Cochrane review rated the interventions into one of the six categories: general physiotherapy, exercise, treadmill training, cueing, dance and martial arts [9]. However, it is not know the effect of these neurorehabilitation therapies in respiratory function of individuals with PD. 
Even if breathing dysfunction is a major cause of death in PD, assessment and treatment of respiratory function is not common in clinical practice. The aim of this study was to compare the effects of functional training and cycle exercise in respiratory function of elderly with PD.

\section{Methods}

We performed a pilot randomised controlled clinical trial with blinded assessment. The study was conducted at the Centro de Referência Estadual de Atenção à Saúde do Idoso (CREASI) (State Reference Health Care Centre for Elderly), a public reference outpatient clinic for the elderly in Salvador, Bahia, Brazil. Data were collected in the period between June/2015 and June/2016. The trial design followed the recommendations of the Consolidated Standards of Reporting Trials (CONSORT) [10]. This is an exploratory analysis of clinical trial registered under ClinicalTrials.gov (clinical trial identifier: NCT02622737). The study was carried out in accordance with the Declaration of Helsinki and approved by the Ethics Human Research Committee of the Institute of Health Sciences - Federal University of Bahia (ref $n^{\circ} 1.016 .971$ ). All participants provided voluntary written informed consent.

\section{Population and sample}

The sample consisted of 20 elderly patients with PD divided randomly into two equal groups. The method of sequence generation was determined with a computerized random number generator. Participants of CG underwent functional training based on conventional therapeutic exercises and the EG performed an aerobic training on a stationary bike.

Elderly candidates with idiopathic PD according to the London Brain Bank Criteria were recruited and included in the study according to the following inclusion criteria: $\geq 60$ years-old, regular use of medication for PD and stage 2, 2.5 or 3 according to modified Hoehn and Yahr scale. The exclusion criteria were: regular use of medication for PD modified Hoehn and Yahr stages 2, 2.5 or 3 (the interventions were developed for patients with bilateral disease involvement without severe disability). The exclusion criteria were: visual or hearing impairment; parkinsonian syndromes other than PD; bone, joint or muscle diseases that limit the practice of physical activity; chronic uncontrolled diseases (hypertension, diabetes mellitus, chronic pain); unstable cardiovascular disease (acute heart failure, recent myocardial infarction, unstable angina and arrhythmias uncontrolled); current alcohol and other toxic substance use; contraindications for performing physical exercise according to the American College of Sport Medicine; practicing any physical exercise program in the last 6 months or participating in regular resistance training ( $\geq 2$ times per week) in the previous 12 months.

\section{Evaluation procedures}

Unified Scale Evaluation of Parkinson's disease (UPDRS) was used to evaluate the clinical and functional status of all participants [11].

We evaluated the thoracoabdominal amplitude, respiratory muscle strength, forced vital capacity (FVC) and forced expiratory volume in the first second $\left(\mathrm{FEV}_{1}\right)$. All participants were evaluated before and after treatment by a single blinded researcher.

The thoracoabdominal amplitude measure was obtained in centimetres by cirtometry. The measurement was performed horizontally into three levels: axillary, xiphoid and abdominal. In the axillary region the tape was placed below axillary fold. We used the lower edge of the xiphoid to measure xiphoid amplitude, and to check abdominal amplitude, we used average distance between xiphoid process and umbilicus [12]. The participants were examined in standing position. In each benchmark were performed three maximum inspiration and expirations under the examiner's voice command. Three values were noted and the differences obtained between inhalation and exhalation (amplitude coefficient). For data analysis was considered the highest value obtained [13].

Respiratory muscle strength was evaluated using a manometer. During evaluation, a nose clip was used to prevent escape of air. The individual held a maximum respiratory effort kept for at least one second, with verbal encouragement by evaluator. Maximal inspiratory pressure (MIP) and maximal expiratory pressure (MEP) were performed at least three and at most six times to eliminate the learning effect and obtain values less than $10 \%$ difference [14]. 
Spirometry was performed to evaluate FVC and $\mathrm{FEV}_{1}$, respecting technical procedures, acceptability and reproducibility criteria, according to the standards of American Thoracic Society and European Respiratory Society [15].

\section{Intervention procedures}

The sessions were performed in all groups lasted 8 weeks with a frequency of three 50-minutes sessions per week. Each session consisted in 10 minutes of stretching (hamstrings, quadriceps, triceps sural, paraspinal, pectoralis minor and major, biceps, deltoid, trapezius, rhomboids, flexors and extensors of the wrist); 5 minutes of calisthenics exercises, 30 minutes of intervention and 5 minutes of breathing exercises (diaphragmatic breathing exercises and costal expansions) to slowdown. The heart rate, oxygen saturation and blood pressure were measured before training, after 15 minutes and at the end of each session. The participants with more than 1 missing a week or more than 4 faults were considered losses. and consisted of an exercise circuit consisting of 10 activities lasting 3 minutes each one. Among the functional activities the following stations were: 1) Gait with obstacles; 2) Going up and down stairs and ramp; 3) Sitting and standing exercises; 4) Side gears; 5) Balance exercise in proprioceptive platform; 6) Activities with balls; 7) Step exercises; 8) Foot tip exercises; 9) Graded reaching activities; 10) Gait training. The intensity evolution was performed progressively with barbells and manual resistance, achieving the individual perception of 15 points on Borg scale [17].

Participants of EG performed an aerobic training on stationary bike lasting 30 minutes. The intensity of the training in the first week was $50 \%$ of maximum heart rate and gradually increased to reach $75 \%$ in the eighth week. The Karvonen formula [18] was used to determine heart rate training goals for each session. Heart rate training was calculated using the equation: (MHR - HRR) $\mathrm{x}$ intensity + HRR. The maximum heart rate (MHR) was estimated by the equation (220 - age) and resting heart rate (HRR) was checked before starting the workout after 10 minutes of rest, with the patient in seated.

In addition, patients should be in a period "on" of PD and taking antihypertensive medications, in case of hypertension.
Statistical analysis

Variables were expressed as median and interquartile range. To compare independent and paired variables was used nonparametric tests as Mann-Whitney and Wilcoxon test. The significance level used was $5 \%(\mathrm{p}<0.05)$.

\section{Results}

The study began with 24 participants, but only 20 patients finished the treatment protocol (Figure 1). The participants were evaluated before and after the therapeutic programs. One participant was excluded because it had more than two absences per week, two subjects abandoned the study and one fractured his ankle at home.

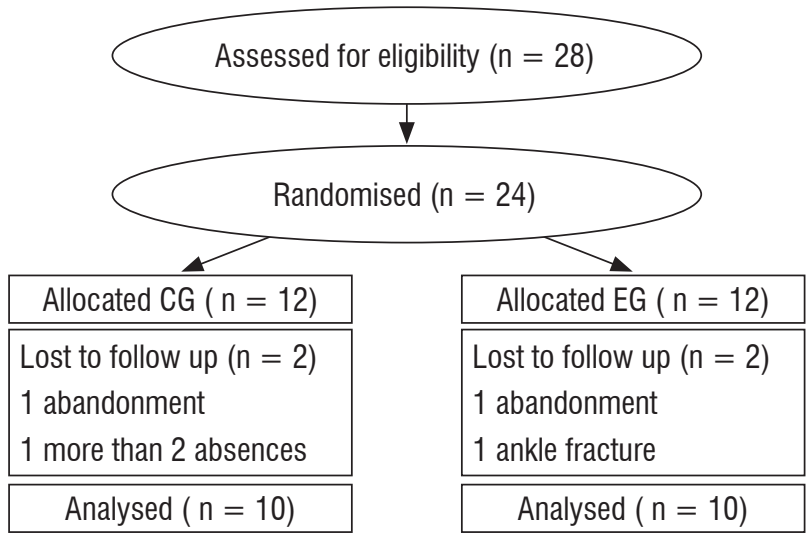

Figure 1 - Flow diagram of the progress through the phases of a parallel randomised trial of two intervention groups. Salvador, Brazil, 2016.

Table 1 shows no difference between demographic and clinical characteristics of the two groups.

Table 1 - Baseline demographic and clinical characteristics (p-values refer to Mann-Whitney test). Salvador, Bahia, Brazil, 2016.

\begin{tabular}{lccc}
\hline Variable & $\begin{array}{c}\text { CG }(\mathbf{n}=\mathbf{1 0}) \\
\text { Median (IR) }\end{array}$ & $\begin{array}{c}\text { EG }(\mathbf{n}=\mathbf{1 0}) \\
\text { Median (IR) }\end{array}$ & $\mathbf{p}$ \\
\hline Age (years) & $67(65-73)$ & $68(63-75)$ & 0.90 \\
BMl $\left(\mathrm{Kg} / \mathrm{m}^{2}\right)$ & 26.24 & 25.55 & 0.59 \\
Hoehn \& Yahr & $(23.76-30.57)$ & $(22.70-29.10)$ & \\
UPDRS & $2.75(2.50-3.00)$ & $2.50(2.00-3.00)$ & 0.31 \\
Illness time (years) & 23.50 & 24.00 & 0.58 \\
\hline
\end{tabular}

Note: Number of participants; m: meters; IR: interquartile range; Kg: kilogram; BMI: body mass index; UPDRS: Unified Parkinson's Disease Rating Scale. 
Table 2 and 3 show the CG and EG results of respiratory function before and after 8 weeks of intervention. The CG showed significant improvements in FVC $(p=0.01)$. There were no significant differences for the other variables in both groups (Table 2).

Table 2 - Summary results for each study group (p-values refer to Wilcoxon test). Salvador, Bahia, Brazil, 2016.

\begin{tabular}{|c|c|c|c|c|}
\hline Variable & $\begin{array}{l}\text { CG }(\mathrm{n}=10) \\
\text { Baseline } \\
\text { median (IR) } \\
8 \text { months } \\
\text { median (IR) }\end{array}$ & p & $\begin{array}{c}\text { EG }(n=10) \\
\text { Baseline } \\
\text { median (IR) } \\
8 \text { months } \\
\text { median (IR) }\end{array}$ & $\mathrm{p}$ \\
\hline FVC (\%) & $\begin{array}{c}91.50 \\
(66.50-109.00) \\
122.00 \\
(72.75-159.00)\end{array}$ & 0.01 & $\begin{array}{c}75.00 \\
(72.00-92.50) \\
92.00 \\
(79.00-112.50)\end{array}$ & 0.50 \\
\hline FEV1 (\%) & $\begin{array}{c}71.50 \\
(63.75-99.25) \\
71.00 \\
(62.50-97.75)\end{array}$ & 0.95 & $\begin{array}{c}93.00 \\
(81.50-103.50) \\
85.00 \\
(77.00-95.50)\end{array}$ & 0.06 \\
\hline MIP $\left(\mathrm{cmH}_{2} \mathrm{O}\right)$ & $\begin{array}{c}-64.00 \\
(-48.25-104.88) \\
-71.50 \\
(-58.75-88.25)\end{array}$ & 0.72 & $\begin{array}{c}-68.00 \\
(-76.00-62.00) \\
-70.00 \\
(-85.00-42.00)\end{array}$ & 0.68 \\
\hline $\operatorname{MEP}\left(\mathrm{cmH}_{2} \mathrm{O}\right)$ & $\begin{array}{c}60.00 \\
(40.75-91.60) \\
70.00 \\
(51.50-112.75)\end{array}$ & 0.13 & $\begin{array}{c}56.00 \\
(42.00-60.00) \\
60.00 \\
(44.00-80.00)\end{array}$ & 0.34 \\
\hline $\mathrm{AAC}(\mathrm{cm})$ & $\begin{array}{c}6.00 \\
(3.75-7.00) \\
6.00(6.00-7.00)\end{array}$ & 0.14 & $\begin{array}{c}6.00 \\
(4.25-9.25) \\
7.00(5.00-9.00)\end{array}$ & 0.68 \\
\hline XAC (cm) & $\begin{array}{c}5.00 \\
(2.12-7.00) \\
5.00 \\
(4.00-6.25)\end{array}$ & 0.43 & $\begin{array}{c}5.00 \\
(3.75-8.00) \\
6.00 \\
(4.50-9.00)\end{array}$ & 0.49 \\
\hline UAC (cm) & $\begin{array}{c}3.50 \\
(0.75-5.00) \\
4.50 \\
(-0.50-7.00)\end{array}$ & 0.73 & $\begin{array}{c}-1.00 \\
(-4.50-3.00) \\
4.00 \\
(-0.50-7.00)\end{array}$ & 0.14 \\
\hline
\end{tabular}

Note: Number of participants; $\mathrm{cm}$ : centimetres; IR: interquartile range; FVC: forced vital capacity; FEV1: expiratory volume in the first second; MIP: maximal inspiratory pressure; MEP: maximal expiratory pressure; AAC: axillar amplitude coefficient; XAC: xiphoid amplitude coefficient; UAC: umbilical amplitude coefficient.

Comparing before and after training values, EG (Table 3) increased not significantly FVC, MEP, MIP, abdominal and xiphoid amplitude.
Table 3 - Comparison of respiratory parameters between groups, before and after interventions ( $p$-values refer to Man-Whitney test). Salvador, Bahia, Brazil, 2016.

\begin{tabular}{lccc}
\hline Variable & $\begin{array}{c}\text { CG }(\mathbf{n}=\mathbf{1 0}) \\
\text { Difference (IR) }\end{array}$ & $\begin{array}{c}\text { EG }(\mathbf{n}=\mathbf{1 0}) \\
\text { Difference (IR) }\end{array}$ & $\mathbf{p}$ \\
\hline FVC (\%) & $14.50(3.25-61.50)$ & $7.00(-8.25-39.50)$ & 0.290 \\
FEV1 (\%) & $-3.00(-9.50-10.00)$ & -5.50 \\
& $1-7.25-21.75)$ & 0.940 \\
MIP $\left(\mathrm{cmH}_{2} 0\right)$ & $(-28.87-25.25)$ & $(-29.50-17.25)$ & 0.520 \\
& 11.00 & 19.00 \\
MEP $\left(\mathrm{cmH}_{2} 0\right)$ & $(-5.25-32.50)$ & $(-6.25-30.00)$ & 0.705 \\
AAC $(\mathrm{cm})$ & $0.00(-0.12-2.25)$ & $1.00(-0.62-2.00)$ & 0.760 \\
XAC $(\mathrm{cm})$ & $0.5(-1.00-1.87)$ & $1.00(1.00-2.12)$ & 0.314 \\
UAC $(\mathrm{cm})$ & $0.00(-2.00-4.12)$ & $0.00(-2.25-5.12)$ & 0.878 \\
\hline
\end{tabular}

Note: Number of participants; $\mathrm{cm}$ : centimetres; IR: interquartile range; FVC: forced vital capacity; FEV1: expiratory volume in the first second; MIP: maximal inspiratory pressure; MEP: maximal expiratory pressure; AAC: axillar amplitude coefficient; XAC: xiphoid amplitude coefficient; UAC: umbilical amplitude coefficient.

No difference between groups was observed (Table 3).

\section{Discussion}

According to our results functional exercise programme and cycle training improved respiratory function of elderly with PD. Although only functional training group increased significantly the lung volume capacity, no difference was observed between the two groups.

Studies suggest that physiologic use of exercise can be an important component of neuroplastic changes in human PD brain and support the central hypothesis that self-produced activity is important in slowing, halting or reversing human PD [19]. However, physical activity seems to be insufficient to improve respiratory function. A multicentre randomised controlled clinical trial has evaluated the effect of physical activity on respiratory outcomes in community-dwelling elders with mobility limitations [20]. Their physical activity programme was like our functional training, and included walking and strength, flexibility and balance training. In comparison to the health education group, physical 
activity was insufficient to improve dyspnoea severity, FEV1 or MIP. In our study we have found similar results in respiratory parameters of elderly with PD trained with cycling exercise and functional training.

However, the combination of aerobic exercise and resistance training improved respiratory parameters in patients with moderate to severe chronic obstructive pulmonary disease. Twenty-four sessions, three times a week involving 40 minutes on treadmill with a load of $80 \%$ of maximal incremental test, 30 minutes of arms exercise with two diagonal movements and 20 minutes of stretching or relaxation improved respiratory muscles strength in patients with chronic obstructive pulmonary disease [21]. Therefore, the combined-training (unsupported training for upper limbs and endurance training by treadmill for lower limbs) decreased dyspnoea of this population. Possibly the high intensity workload $(80 \%)$ may explain this significant improvement of respiratory muscles. Even if physiopathology of muscle strength loss is different between PD and chronic pulmonary disease, both patients presented muscle endurance reduction. Lower training intensities used in cycling exercise and functional training may have influenced our results.

Maybe respiratory exercises should be necessary to improve respiratory parameters in patients with PD. Respiratory exercises include diaphragmatic and costal breathing, mobilization and stretching of the trunk, cervical region and external intercostal, deep inspiration and incentive spirometry. By performing five months of respiratory exercises, Alves et al. [22] found improvement in respiratory symptoms in a 47-year-old male patient in stage IV Hoehn \& Yahr scale. Their results showed improvements in FVC, FEV1, MIP and MEP, peak expiratory flow (PEF) and Maximum Voluntary Ventilation (VVM). Our patients also have done trunk and cervical stretching and diaphragmatic and costal breathing, performed 3 times a week during 8 weeks. However, it was not sufficient to improve respiratory function. Koseoglu et al. [23] also used respiratory exercises in patients with PD I and II Hoehn \& Yahr stages and found similar results. They performed diaphragmatic, deep-breath exercises, voluntary hyperpnoea, and strengthening of upper limbs and found similar improvements in spirometry, dyspnoea index and exercise capacity.

Respiratory kinesiotherapy is another intervention procedure consisting of an exercise program combined with diaphragmatic re-education, costal breathing, thoracic, cervical and shoulder girdle mobilization, stretching of the accessory respiratory muscles, deep-breathing exercises and incentive spirometry training. The study of Pereira et al. [24] verified the effect of respiratory kinesiotherapy in three men, aged 65 years, with idiopathic PD, in stages 2.5 and 3 Hoehn \& Yahr scale. At two months, after performing 16 sessions of 30 minutes, it was observed good improvements of lung volume and compliance. These findings also support the necessity of respiratory exercises to improve pulmonary parameters of patients with PD.

Another complementary physiotherapeutic treatment is the Isotretching method. This therapy acts on the imbalances that affect posture, contributing to the improvement of range of motion, muscular strength, body awareness, respiratory capacity and diaphragmatic mobility. Palacio et al. [25] compared the effects of 20 sessions of hydrotherapy and Isotretching method on the pulmonary capacity of patients with PD aged 45 - 65 years old. Although they did not perform a specific respiratory training, they observed statistically significant improvement of the MIP, MEP, FVC and FEV1 in both training groups, which was not found in our study.

Another way to improve respiratory function is associating respiratory muscle training with motor therapy. The study conducted by Moreira et al. [26] have submitted PD patients to respiratory muscle training with threshold, $40 \%$ of MIP and MEP protocol, associated with whole body vibration therapy in 24 sessions for two months. The participants, aged 45 to 80 years old, presented stage 3 of the Hoehn \& Yahr classification. They observed an increase in MIP and MEP values, that is, an improvement on respiratory muscle resistance after intervention. These findings demonstrate that the combination of physical and respiratory training may also be able to provide positive results on respiratory functions. A clinical trial conducted by Inzelberg et al. [27] also investigated the effect of inspiratory muscle training on lung function, inspiratory muscle performance, dyspnoea and quality of life of 20 patients with PD in stage 2 or 3 of Hoehn \& Yahr scale. The training performance was conducted using 15\% of MIP, which increased progressively each session until reaching $60 \%$ at the end of the first month. The CG was trained with a very low fixed load of $7 \mathrm{cmH} 20$. At the end of 17 sessions, the experimental group improved 
inspiratory muscle performance and a significant decrease in dyspnoea perception.

The practice of physical activity on a regular basis increase aerobic capacity and cardiac output [28] Pelosin et al. [29] reported that individuals with PD spend approximately $20 \%$ more energy than healthy controls when exercising on treadmill or cycle ergometer. Beneficial changes in hemodynamic, hormonal, metabolic and respiratory functions may also occur with increased ability to perform physical exercises.

Hydrotherapy, Halliwick method, is another modality of training used to treat patients with PD. Espindola et al. [30] have evaluated the effects of hydrotherapy on respiratory function of five elderly patients with PD. The treatment consisted of ten points: mental adjustment, detachment, control of longitudinal rotation, control of sagittal rotation, control of horizontal rotation, control of combined rotation, thrust, balance, turbulence/ slip, simple progressions and basic swimming. They have evaluated thoracic expansibility by cirtometry, cardiopulmonary fitness using 6-minute walk test, and pulmonary flow and volumes with flowmetry and ventilometry. The study results demonstrated beneficial effects of Halliwick method on respiratory function of participants in all variables studied without performing a specific respiratory training.

The main limitation of the study is represented by the small sample size.

Further research is needed to determine the optimal exercise training to improve the respiratory function of patients with PD.

\section{Conclusion}

The functional training based on conventional therapeutic exercises, the most used treatment for patients with PD, as well as aerobic exercise cycling training seem to modify, but not significantly the respiratory parameters of elderly with PD. It is noteworthy that elderlies of the two groups did not obtain losses in respiratory capacity after 8 weeks of intervention period. Studies indicate that the specific training for the respiratory function seems to be essential for changes in the respiratory parameters of this population.

\section{References}

1. Gelb DJ, Oliver E, Gilman S. Diagnostic criteria for Parkinson disease. Arch Neurol. 1999;56(1):33-9.

2. Haas BM, Trew M, Castle PC. Effects of respiratory muscle weakness on daily living function, quality of life, activity levels and exercise capacity in mild to moderate Parkinson's disease. Am J Phys Med Rehabil. 2004;83(8):601-7.

3. Cardoso SRX, Pereira JS. Análise da função respiratória na doença de Parkinson. Arq Neuro-Psiquiatr. 2002;60(1):91-5.

4. Pitts T, Bolser D, Rosenbek J, Troche M, Okun MS, Sapienza C. Impact of expiratory muscle strength training on voluntary cough and swallow function in Parkinson disease. Chest. 2009;135(5):1301-8.

5. Vieira FDM. Plataforma de Apoio à Terapia de Reabilitação e Manutenção de Doentes de Parkinson [master's thesis]. Porto, PT: Universidade de Porto; 2013. $48 \mathrm{p}$.

6. Loureiro APC, Ribas CG, Zotz TGG, Chen R, Ribas F. Viabilidade da terapia virtual na reabilitação de pacientes com doença de Parkinson: estudo-piloto. Fisioter Mov. 2012;25(3):659-66.

7. Panizzi EA, Nunes AC, Borba C, Kerkoski E. Mobilidade torácica em estudantes na faixa etária de 8 a 14 anos de ambos os sexos: uma análise descritiva. VIII Encontro Latino-Americano de Iniciação Científica e IV Encontro Latino-Americano de Pós-Graduação; 2004 Oct 21-22; São José dos Campos. São José dos Campos: Universidade do Vale do Paraíba; 2004.

8. Lopes RB, Brito RR, Parreira VF. Padrão respiratório durante o exercício - revisão literária. R Bras Cienc e Mov. 2005;13(2):153-60.

9. Tomlinson CL, Herd CP, Clarke CE, Meek C, Patel S, Stowe R, et al. Physiotherapy for Parkinson's disease: a comparison of techniques. Cochrane Database Syst Rev. 2014;(6):CD002815.

10. Schulz KF, Altman DG, Moher D; CONSORT Group. CONSORT 2010 statement: updated guidelines for reporting parallel group randomized trials. Obstet Gynecol. 2010;115(5):1063-70. 
11. Goetz CG, Fahn S, Martinez-Martin P, Poewe W, Sampaio C, Stebbins GT, et al. Movement Disorder Societysponsored revision of the Unified Parkinson's Disease Rating Scale (MDS-UPDRS): Process, format, and clinimetric testing plan. Mov Disord. 2007;22(1):41-7.

12. Rocha PA, McClelland J, Morris ME. Complementary physical therapies for movement disorders in Parkinson's disease: a systematic review. Eur J Phys Rehabil Med. 2015;51(6):693-704.

13. Abbruzzese G, Marchese R, Avanzino L, Pelosin E. Rehabilitation for Parkinson's disease: Current outlook and future challenges. Parkinsonism Relat Disord. 2016;22(Suppl 1):S60-4.

14. Black LF, Hyatt RE. Maximal respiratory pressures: normal values and relationship to age and sex. Am Rev Respir Dis. 1969;99(5):696-702.

15. Miller MR, Hankinson J, Brusasco V, Burgos F, Casaburi $\mathrm{R}$, Coates A, et al. Standardisation of spirometry. Eur Respir J. 2005;26(2):319-38.

16. Canning CG, Sherrington C, Lord SR, Close JC, Heritier $\mathrm{S}$, Heller GZ, et al. Exercise for falls prevention in Parkinson disease: a randomized controlled trial. Neurology. 2015;84(3):304-12.

17. Wilson RC, Jones PW. A comparison of the visual analogue scale and modified Borg scale for the measurement of dyspnoea during exercise. Clin Sci (Lond). 1989;76(3):277-82.

18. Whaley $\mathrm{MH}$, Brubaker $\mathrm{PH}$, Otto RM, Armstrong LE. ACSM's guidelines for exercise testing and prescription. 7th ed. Philadelphia: Lippincott Williams \& Wilkins; 2006.

19. Hirsch MA, Iyer SS, Sanjak M. Exercise-induced neuroplasticity in human Parkinson's disease: What is the evidence telling us? Parkinsonism Relat Disord. 2016;22 (Suppl 1):S78-81.

20. Fragoso CAV, Beavers DP, Anton SD, Liu CK, McDermott MM, Newman AB, et al. Effect of Structured Physical Activity on Respiratory Outcomes in Sedentary Elderly Adults with Mobility Limitations. J Am Geriatr Soc. 2016;64(3):501-9.

21. Basso-Vanelli RP, Di Lorenzo VA, Labadessa IG, Regueiro EM, Jamami M, Gomes EL, et al. Effects of Inspiratory Muscle Training and Calisthenics-and-Breathing Exercises in COPD With and Without Respiratory Muscle Weakness. Respir Care. 2016;61(1):50-60.
22. Alves LA, Coelho AC, Brunetto AF. Fisioterapia respiratória na Doença de Parkinson idiopática. Fisioter Pesqui. 2005;12(3):46-9.

23. Köseoglu F, Inan L, Özel S, Deviren SD, Karabiyikoglu G, Yorgancioglu R, et al. The effects of a pulmonary rehabilitation program on pulmonary function tests and exercise tolerance in patients with Parkinson's disease. Funct Neurol. 1997;12(6):319-25.

24. Pereira FF, Assumpção FF, Rosa JS, Lima MIL, Gonçalves MCP, Faria L. Efeito da fisioterapia respiratória em portadores da Doença de Parkinson. Rev Fisioter Ser. 2010;5(4):235-40.

25. Palácio SG, Barroca JB, Toldo KF, Ramalho JBL, Vanzela AL, Facci LM. Estudo comparativo entre a hidroterapia e a cinesioterapia na Doença de Parkinson. Rev Saúde Pesqui. 2011;4(2):191-9.

26. Moreira AM, Galvão MLC, Araújo HAG, Silva AT, Reis LM, Silva AM, et al. Treino muscular respiratório e terapia vibratória em pacientes com doença de Parkinson. Rev Neurocienc. 2015;23(3):479-85.

27. Inzelberg R, Peleg N, Nisipeanu P, Magadle R, Carasso RL, Weiner P. Inspiratory Muscle Training and the Perception of Dyspnea in Parkinson's Disease. Can J Neurol Sci. 2005;32(2):213-7.

28. Cavalca C, Soldi F. Avaliação de Aptidão Física em Pacientes com Doença de Parkinson submetidos a tratamento hidroterápico através do Método Halliwick [undergraduate thesis]. Florianópolis (SC): Universidade do Sul de Santa Catarina; 2004. 29 p.

29. Pelosin E, Faelli E, Lofrano F, Avanzino L, Marinelli L, Bove $\mathrm{M}$, et al. Effects of treadmill training on walking economy in Parkinson's disease: a pilot study. Neurol Sci. 2009;30(6):499-504.

30. Espindola AR. Avaliação respiratória em pacientes com doença de Parkinson submetidos ao método Halliwick [undergraduate thesis]. Tubarão, SC: Universidade do Sul de Santa Catarina; 2005. 86 p.

Received in 08/01/2017

Recebido em 01/08/2017

Approved in 10/16/2017

Aprovado em 16/10/2017 